\title{
A la luz del Tratado de Lisboa: génesis y evolución del entramado institucional de la Unión Europea
}

Raynier Pellón Azopardo*

RESUMEN

A la luz del Tratado de Lisboa, y considerando los cuestionamientos que en términos de cohesión política y económica enfrenta el proceso integracionista de la Unión Europea (UE), resulta loable evaluar el alcance y los rasgos específicos del entramado institucional de la Unión.

Las reformas contempladas en el Tratado de Lisboa de la UE, instrumentadas en medio de la mayor crisis económica que ha vivido el modelo capitalista, constituyeron la respuesta del liderazgo comunitario ante la necesidad de paliar múltiples vulnerabilidades que afronta el proceso integracionista.

Vistos en su evolución, en el artículo se destacan rasgos característicos del entramado institucional de la UE, así como la profundización y las contradicciones implícitas del proceso integracionista.

Palabras clave: Unión Europea, Tratado de Lisboa, crisis institucional, integración.

\section{In light of the Treaty of Lisbon: Genesis and evolution of the institutional framework of the European Union}

\section{ABSTRACT}

In light of the Lisbon Treaty and considering the issues that the integration process of the

\footnotetext{
* Máster en Historia Contemporánea y Relaciones Internacionales, Universidad de La Habana. Investigador del Centro de Investigaciones de Política Internacional, La Habana (Cuba) [raynier@cipi.cu].

Recibido: 12 de marzo de 2016/ Modificado: 10 de mayo de 2016/ Aceptado: 23 de junio de 2016

Para citar este artículo

Pellón Azopardo, R. (2017). A la luz del Tratado de Lisboa: génesis y evolución del entramado institucional de la Unión Europea. OAsIs, 25, 41-61.

DOI: https://doi.org/10.18601/16577558.n25.03
} 
European Union (EU) is facing in terms of political and economic cohesion, it is worthwhile assessing the scope and specific features of the institutional framework of the Union.

The reforms envisaged in the Lisbon Treaty of the EU, implemented in the midst of the greatest economic crisis that the capitalist model has gone through, constituted the response of the community's leadership to the need of alleviating multiple vulnerabilities facing the integration process.

As observed in its evolution, the article highlights characteristic features of the institutional framework of the EU and the deepening and implicit contradictions of the integration process.

Key words: European Union, Lisbon Treaty, institutional crisis, integration.

A la luz del Tratado de Lisboa, y considerando los cuestionamientos que en términos de cohesión política y económica enfrenta el proceso integracionista de la Unión Europea (UE), resulta loable evaluar el alcance y los rasgos específicos del entramado institucional de la Unión.
Visto en su evolución, la UE que hoy conocemos continúa siendo un proceso en construcción. El tratado que consagra oficialmente su nombre no significó el comienzo ni la conclusión de la integración iniciada con la Comunidad Europea del Carbón y del Acero (CECA) en 1951, sino una etapa más de esta ${ }^{1}$.

Desde entonces, la sistemática institucionalización de la Unión se encuentra permeada, en medio de indiscutibles avances, por trascendentales contradicciones.

La integración ha implicado abordar uno de los elementos claves de la cultura euro-occidental desde comienzos de la Edad Moderna, como lo era $-\mathrm{y}$ en buena medida lo sigue siendo- la soberanía estatal. Diversos actores, apoyados en el clásico concepto de soberanía estatal, han ralentizado la profundización del proceso, particularmente en el ámbito político, y han apoyado implícitamente nacionalismos, exclusivismos étnicos, religiosos o reivindicaciones territoriales.

Los propios propulsores de la primera comunidad $^{2}$ comprendieron que el proceso integracionista debía superar los estrechos límites de la soberanía estatal, comprendida como poder absoluto, indivisible, autónomo,

Con Maastricht, conocido también como Tratado de la Unión Europea (TUE), se modifica y completa el de París de 1951(que creó la CECA), los de Roma de 1957 (que instituyeron la CEE y el EURATOM) y el Acta Única Europea de 1986.

2 Robert Schuman (Francia, 1886-1963). Presidente del Consejo en 1947 como miembro del Movimiento Republicano Popular (MRP), después ministro de Finanzas, de Justicia y de Asuntos Exteriores (1948-1952); este último cargo lo llevó a ser el mayor negociador francés de los tratados firmados entre el final de la Segunda Guerra Mundial y el principio de la Guerra Fría: Consejo de Europa, otAN, CECA, etc. Jean Monnet (Francia, 1888-1979) concibió la estrategia de comenzar por la integración económica de Europa, para fomentar así una solidaridad material que contrarrestara los particularismos nacionales y fuera la base para una futura unión política. 
independiente e impermeable, expresión para referirse a la inviolabilidad territorial y a la exclusividad de la autoridad estatal dentro de un territorio, que implica para los demás la obligación de tratarla como una entidad monolítica (Burgerman, 2003).

Sin embargo, el enfrentamiento entre los partidarios de superar las instituciones internacionales de tipo clásico (intergubernamental), y aquellos que subordinan las prioridades del proceso de integración y su dinámica institucional a los intereses nacionales, sigue siendo característico del entramado comunitario.

La histórica proyección de Reino Unido resulta ilustrativa. Londres ha defendido particularmente la dimensión económica y comercial del proceso integracionista, y al propio tiempo ha evidenciado abiertas reticencias ante las transferencias de competencias nacionales en los órdenes políticos, de seguridad, y, específicamente monetario.

En cambio, la política de Alemania -aunque también defensora de intereses nacionales y de su liderazgo en los marcos de la Unión- favorece el fortalecimiento de la UE como "actor global" (Global Security Actor) con influencia política y formador del Orden Internacional, apostando por el fortalecimiento de las instituciones europeas y una mayor incidencia en el contexto internacional.

Rememorar las conflagraciones que han condicionado la evolución económica, sociopolítica y cultural de Europa también nos permite vislumbrar la magnitud de los resultados que en materia de integración se han alcanzado hasta el momento. Basta resaltar que el territorio donde se erige la uE fuera epicentro de la Segunda Guerra Mundial, con- flicto que influyó de manera determinante en el declive de la hegemonía euro-occidental, y en el surgimiento de un nuevo orden mundial liderado por Estados Unidos y la URss.

Consecuentemente, y en medio del contexto de la Guerra Fría, el proceso integracionista de la UE nació como un esfuerzo por recobrar el activismo económico de preguerra y responder al propósito de garantizar la paz entre sus Estados miembros. Otro objetivo implícito quedaba zanjado: contener la influencia ideo-política y económica de la URSs, y al propio tiempo, constituirse en un referente para las repúblicas socialistas del Este europeo.

Un propósito menos loable y publicitado que la intención de alcanzar la paz entre los Estados miembros, pero que hoy constituye directriz esencial de la integración comunitaria, radica en garantizar -en primera instancia- los intereses del capital transnacional. La profundización del proceso integracionista de la UE, y la dinámica de su complejo entramado institucional, también persiguen el propósito de insertarse, en un marco de eficiencia y competitividad, en la fase actual de las relaciones de producción capitalista, o lo que se ha dado en llamar, los fines del proceso de globalización.

Dicho proceso debe entenderse como la tercera etapa en el proceso de expansión internacional de las relaciones de producción capitalistas. En su nivel actual, se expresa en la creciente interdependencia e interconexión de los mercados, las mercancías, los capitales y las naciones, lo cual conduce a un proceso de readaptación del mecanismo económico, estableciendo un nuevo paradigma tecno-organizativo. Su fundamento teórico son las concepciones neoliberales, de ahí su 
denominación de globalización neoliberal, cuyos postulados básicos son el imperio del mercado, la redefinición del papel del Estado, la desregulación económica, la privatización, el libre movimiento de capitales y mercancías, la apertura al capital extranjero y la contención de las conquistas de la clase obrera. Es un fenómeno esencialmente -pero no exclusivamente- económico. Como fenómeno complejo y multidimensional, incluye tendencias científico-técnicas, económicas, sociales, políticas, institucionales y teórico-conceptuales ${ }^{3}$.

La supranacionalidad fomentada por la aproximación comunitaria al proceso de globalización, lejos de garantizar la pretendida cohesión económica de sus Estados miembros, ha implicado una alta concentración del poder económico, comercial, financiero y científico-técnico en un número reducido de actores económicos, llevando aparejado el paulatino surgimiento y desarrollo de su contrario: la exclusión de un número de ciudadanos, y las crecientes asimetrías económicas, sociales y políticas existentes entre los países y las regiones de la UE.

La situación general se asocia al desgaste de la legitimidad democrática de la ue, la exacerbación del euroescepticismo y el descrédito de sus instituciones ante ciudadanos y fuerzas políticas comunitarias.
Con los mencionados elementos como premisas, durante la Presidencia Semestral de Portugal (julio a diciembre de 2007) fueron allanados los principales escollos en función de materializar el Tratado de Lisboa. Según la visión del Ejecutivo comunitario, las reformas contempladas en el Tratado de Funcionamiento de la uE dinamizarían el anquilosado funcionamiento de la Unión y fortalecerían la debilitada cohesión del bloque ${ }^{4}$.

$\mathrm{Al}$ respecto, José Sócrates 5 afirmó solemnemente: "ha nacido el nuevo Tratado de Lisboa. Es una victoria de Europa, que sale de un impasse de muchos años y supera su crisis institucional" (El País, s. f.).

Las declaraciones de José Sócrates y el optimismo manifiesto de parte estimable del liderazgo comunitario dejan, al menos, una interrogante sobre la cual reflexionar: ¿a la luz del Tratado de Lisboa, puede hablarse en términos absolutos del fin de la crisis institucional de la UE?

Responder esta y otras interrogantes a lo largo del artículo, aunque en el trabajo no se realicen análisis teóricos, también supone considerar aspectos generales contenidos en teorías de las relaciones internacionales, las teorías de la integración internacional y la teoría del sistema-mundo, la realista, la idealista, la teoría de los conflictos, las teorías

\footnotetext{
3 Concepto elaborado por Baro Herrera (1997).

4 El Tratado de Lisboa está integrado por cuatro documentos: Protocolos, Declaraciones, Tratado de Funcionamiento de la UE y Tratado de la Unión Europea.

5 Exprimer ministro portugués, posteriormente encarcelado por una investigación de blanqueo de dinero.
} 
geopolíticas, la teoría del centro-periferia, de la dependencia, entre otras ${ }^{6}$.

\section{UNA APROXIMACIÓN AL ENTRAMADO INSTITUCIONAL DE LA UE: SU GÉNESIS Y EVOLUCIÓN}

El proceso integracionista tuvo, desde sus orígenes, un carácter sectorial. Han trascendido en un orden supranacional ámbitos básicamente económicos, entre cuyos principales avances hoy se destacan el mercado único, la unión aduanera, la política agraria común y la moneda única que comparten 18 miembros del bloque. Sin embargo, el propósito de alcanzar una mayor cohesión y coordinación en el ámbito exterior, fuera del aspecto comercial, aún constituye un reto para la UE.

Viendo el entramado institucional en su evolución, la Alta Autoridad de la Comunidad Europea del Carbón y el Acero (CECA) constituyó un órgano común que superaba -en cuanto a su estructura, la designación de sus miembros, las competencias y los procedimientos- la clásica organización internacional de tipo intergubernamental.

En ese sentido, la estructura institucional promovida con el Tratado de París, constitutivo de la Ceca (Unión Europea, 1951), estableció las bases para una mayor integración futura de los países miembros. Sin embargo, ya en esta fecha se manifesta- ron fuerzas importantes aferradas al concepto clásico de soberanía del Estado nacional, que rechazaban cualquier intento de avanzar más allá de lo alcanzado por la CECA. El Tratado de Roma (Unión Europea, 1957), por el que quedó instituida la Comunidad Económica Europea (CEE) y Euratom en 1957, también resultó ejemplo perceptible de ello.

En cuanto a sus estructuras institucionales, existieron similitudes con las de la CECA. Contaron con un Consejo de Ministros, representante de los Estados miembros y una Comisión equivalente a la Alta Autoridad para cada Comunidad. Como elemento novedoso fue creado un Parlamento, pretendido representante de los pueblos, que compartió el Poder Legislativo con el Consejo de Ministros. Además, se estableció un Tribunal de Justicia Común, encargado de velar por el cumplimiento del derecho colectivo, es decir, se trataba de un Poder Judicial dotado de poderes y competencias efectivas, que vendría a desempeñar un papel muy importante en la evolución de la integración europea.

La Comisión creada para cada uno de los dos nuevos procesos (EURATOM y CEE) tuvo funciones similares a la Alta Autoridad de la CECA, pues se le atribuyó ser la guardiana de los tratados, tener el monopolio de la iniciativa legislativa y amplias funciones ejecutivas. El Parlamento y el Consejo no ostentaban, de

6 Para acercarnos a los aspectos distintivos de estas teorías se han estudiado obras fundamentales de autores como Hans Morgenthau, George Kennan, Raymond Aron, Henry Kissinger, Alfred T. Mahan, Halford Mackinder, Raúl Prebisch, Ernst B. Haas, Stanley Hoffman, entre muchos otros que nos acercan a la literatura elaborada en materia de relaciones internacionales. 
manera exclusiva, los poderes Legislativo y Ejecutivo respectivamente. Tan solo el Tribunal de Justicia tenía estructura y fines distintos de cualquier otro órgano jurisdiccional.

Entre otras cuestiones, ello explica por qué los avances significativos del proceso integracionista no deben entenderse como la realización clásica de una federación, puesto que su sistema institucional no se corresponde con ningún modelo de derecho público, distinguiéndose en especial de la clásica división tripartita de poderes (Briceño, 1994).

En cuanto a las competencias conferidas a Euratom ${ }^{7}$, ciertamente dejaron de ser exclusivamente nacionales. No obstante, se entregaron a un órgano intergubernamental como el Consejo, de manera que no se rompió claramente con el viejo tipo de organización, aunque sí se redujo el grado de autonomía de los Estados.

En la Comunidad Económica Europea ocurría que la Comisión era más un grupo técnico que un órgano ejecutivo autónomo. Tenía facultades de estudiar, sugerir y proponer medidas en áreas muy diversas, como la liberalización comercial, el transporte, la agricultura y los impuestos; pero, en última instancia, era el Consejo quien aprobaba tales estudios y recomendaciones. El Consejo de Ministros constituía un verdadero poder, aunque el proceso de toma de decisión dependía de la unanimidad de los miembros, ralentizando continuamente su dinámica in- terna. No obstante, el proceso integracionista logró avances importantes en la consecución del mercado único, la unión aduanera y una política agraria común, pasos inéditos en la integración regional.

Ante la evolución del proceso, resultó inadecuado mantener una estructura organizativa propia y separada para cada Comunidad, lo que hizo necesario una coordinación de sus políticas. Con ese fin, en 1967 se firmó en Bruselas un tratado de fusión (Unión Europea, 1965) que creó una Comisión y un Consejo único para las tres comunidades, lo cual perfeccionó la organización comunitaria y creó una mayor red de vinculaciones entre los procesos de integración.

Con este paso se consolidaba la dualidad de soberanías que hoy constituye un rasgo característico del bloque comunitario: la soberanía de los órganos supranacionales, básicamente para los aspectos económicos, menos susceptibles a las críticas de sectores políticos, y la soberanía de los Estados miembros, expresada en el carácter intergubernamental del Consejo, órgano principal de decisión de la Unión.

De esta forma quedó establecido el siguiente marco institucional: la Comisión, encargada de velar por la correcta aplicación de los Tratados; el Consejo de Ministros, sobre el que descansa el poder decisorio; el Parlamento Europeo (PE), elegido por sufragio universal directo a partir de 1979, y cuyos diputa-

\footnotetext{
Promover investigación en el área nuclear; poner en ejecución sus propias patentes y autorizar su explotación a intereses privados; facultad de inspección para evitar su aplicación ilícita; racionalizar precios y racionalizar suministros.
} 
dos se encuentran agrupados por tendencias políticas $^{8}$; y el Tribunal de Justicia, cuya misión es la de asegurar el control jurisdiccional. A estas instituciones se les unió, en 1975, el Tribunal de Cuentas, creado por el Tratado del 22 de julio de 1975, con la misión de controlar los fondos comunitarios, velando por el equilibrio entre ingresos y gastos.

Con la firma del Acta Única Europea (AUE), en 1986 se abrió una nueva etapa en la integración de los entonces doce Estados miembros ${ }^{9}$, en tanto se propusieron superar las diferentes barreras que obstaculizaban la formación de un mercado común. En el ámbito estructural quedó institucionalizado el Consejo Europeo como órgano superior de la cooperación política. Hasta la AUE, tanto el Consejo como la cooperación política no se basaban en texto legal alguno, sino en compromisos políticos ${ }^{10}$.

Entre las modificaciones que en el orden institucional introdujo el AUE, la Comisión adquirió la competencia general de la normativa ejecutiva, a no ser que dicha competencia fuera reservada para sí por el Consejo. Al crearse el procedimiento de cooperación, el Parlamento fue dotado de nuevos poderes de intervención en la elaboración de las normas comunitarias, lo cual le permitió pronunciarse sobre las propuestas de la Comisión Europea y disponer, en ciertos casos, de mayores posibilidades de ver adoptadas sus posiciones. También se requirió la aprobación del PE para el ingreso de nuevos miembros y la firma de acuerdos con terceros países.

Respecto al Consejo, se estableció el voto por mayoría cualificada para las decisiones referentes a la gestión de las nuevas políticas comunitarias y para varios aspectos del mercado interno, pero se mantuvo la unanimidad para los principios directivos de las nuevas políticas. Dentro del mercado interno, las relativas a la armonización fiscal, la libre circulación del personal y los derechos de los trabajadores. Este último factor continuaría obstaculizando la toma de decisiones en este marco y determinando el anquilosamiento del proceso integracionista en diversas áreas.

Especial atención merece el aspecto de la cooperación política, pues mediante ella los Estados buscarían implementar una política exterior europea, formalizando el procedimiento seguido hasta la firma del AUE, es decir, la reunión de los ministros de Relaciones Exteriores y de un miembro de la Comisión para tratar cuestiones de política exterior.

\footnotetext{
8 De manera oficial quedaban constituidas las siguientes funciones para el PE: aprobar la legislación europea conjuntamente con el Consejo, compartir igualmente con el Consejo la autoridad presupuestaria y ejercer el control democrático de las instituciones.

9 1951: Bélgica, Francia, Alemania, Italia, Luxemburgo, Países Bajos; 1973: Dinamarca, Irlanda, Reino Unido; 1981: Grecia; 1986: Espańa y Portugal.

10 La primera Cumbre Europea tuvo lugar en París en 1961, pero hasta 1974, el funcionamiento de los Consejos Europeos tuvo un carácter ocasional, fecha en que se estableció la celebración de dos cumbres ordinarias anuales, correspondientes con el cierre de cada semestre de presidencia, y de un número indeterminado de reuniones extraordinarias. Consultar Perera Gómez (2002).
} 
En resumen, a partir del AUE, la Comunidad Europea evidenció el propósito de alcanzar mayor cohesión en el ámbito exterior, no solo en el aspecto comercial, sino en el aspecto estrictamente político. Sin embargo, a pesar de los avances, el proceso de integración no daría un salto cualitativo en términos políticos hasta 1992, con el Tratado de Maastricht, que planteó entre sus objetivos la creación de una mayor coordinación de las políticas exteriores y de defensa, y mayores competencias para la Comunidad en diversas materias.

Con Maastricht, conocido también como Tratado de la Unión Europea (TUE), por primera vez se sobrepasaba el objetivo económico inicial de la Comunidad (construir un mercado común) y se le daba una vocación de unidad política al proceso de integración (Briceño, 1994).

En el ámbito financiero, mereció una especial consideración el proyecto de crear un sistema monetario y una moneda única. Para su consecución se decidió crear el Instituto Monetario Europeo, encargado de preparar las actividades del Sistema de Bancos Centrales (SEBC) y del Banco Central Europeo, los cuales deberían estar en funcionamiento en 1999.

La estructura de la Unión Europea, de acuerdo con el TUE, quedó basada en tres pilares: el primero, constituido por las tres comunidades europeas, y donde los Estados miembros ejercitaban de conjunto su soberanía en las áreas previstas por los tratados; el segundo y tercer pilares, de carácter inter- gubernamental, lo conformaron la Política Exterior y de Seguridad Común (PEsc), así como la Cooperación en Justicia y Asuntos de Interior (JAI), en las que el Parlamento y la Comisión desempeñan un limitado papel.

En otros órdenes, el liderazgo comunitario se propuso fortalecer las instituciones del bloque, y así el PE vio reforzados sus poderes. En este sentido, se introdujo el procedimiento de codecisión ${ }^{11}$, respaldando que el PE, junto al Consejo deviniera en colegislador. También fueron fortalecidos los poderes de control político y financiero de ambos órganos sobre la Comisión Europea, que a su vez incrementó sus competencias en los ámbitos de salud pública, cultura, protección de los consumidores, educación, industria, redes transeuropeas y cooperación al desarrollo. En este contexto, el Consejo aumentó su capacidad de decisión al ampliar el número de supuestos en que las medidas a seguir solo requerían alcanzar una mayoría cualificada.

En 1997 se firmó un nuevo Tratado en la ciudad de Ámsterdam, que incluyó algunas reformas institucionales, especialmente en lo que respecta al Parlamento Europeo (al que reforzó, al aumentar sus competencias), pero, en general, fue insuficiente e ineficaz en sus modificaciones. Faltaron los acuerdos en temas de gran importancia, como por ejemplo, la futura composición de la Comisión, la ponderación de votos en el Consejo, o la fusión y reestructuración de los tratados en un único texto jurídico. En cuanto a sus "novedades",

11 Procedimiento de codecisión: el Parlamento Europeo puede rechazar, por mayoría absoluta de sus miembros, la posición común adoptada por el Consejo y poner fin al procedimiento. 
estas resultaron, en ocasiones, inviables. Tal fue el caso de las "cooperaciones reforzadas", difíciles de aplicar ante la cantidad de requisitos exigidos. El propio texto, consciente de sus limitaciones, se encargaba de anunciar nuevas reformas antes de la siguiente ampliación de la Unión Europea (Comunidad de Madrid, s. f.).

En el orden político institucional, las continuas reformas consensuadas por los Estados miembros no habían logrado poner a los nuevos miembros en un marco eficaz y dinámico. Con el fin de preparar a la Unión para su quinta ampliación, los socios comunitarios se reunieron en Niza, donde el 26 de febrero de 2001 adoptaron un Tratado modificador del sistema de la Unión Europea, en vigor desde el 1 de febrero de 2003. Este fue ratificado por los quince Estados miembros de la época ${ }^{12}$, y con el propósito de preparar la inminente ampliación, fueron revisados los tratados preexistentes en cuatro ámbitos principales: funciones y composición de la Comisión, ponderación de votos en el Consejo, ampliación de la votación por mayoría cualificada y las cooperaciones reforzadas (Perera, 2002).

El limitado alcance de Niza, en cuanto a la dinámica institucional, resultó evidente tras la incorporación de diez nuevos Estados en el $2004^{13}$. Ello se expresó en la permanencia de grandes problemas que ya venía experimentando el bloque: ineficacia de sus instituciones a partir de una excesiva burocracia, el poder restringido del PE, la ralentización del proceso de toma de decisiones, las agudas divergencias de sus miembros en el ámbito exterior y de defensa, los fuertes contrastes en cuanto a niveles de desarrollo económico y en las posibilidades de los Estados de influir en las diferentes políticas comunes; así como la crisis de legitimidad y credibilidad de sus representantes ante los ciudadanos europeos.

Estas dificultades determinaron sustanciales momentos de crisis, impedían la cohesión del llamado club comunitario y vulneraban su posición ante el balance mundial de poder.

\section{TRATADO DE LISBOA: ¿FIN DE LA CRISIS INSTITUCIONAL?}

Evaluar los aportes e impactos del Tratado de Lisboa, sugiere tanto una interpretación de su contenido, como del contexto comunitario en que fue negociado, aprobado y finalmente implementado dicho acuerdo.

Para el 2007, momento en que se estuviera negociando un nuevo tratado y culminara la quinta ampliación de la $\mathrm{UE}^{14}$, resultaba ostensible la necesidad de enrumbar el proceso integracionista hacia su profundización. En ámbitos académicos y políticos una frase solía resumir la encrucijada que enfrentaba la Unión: "ampliación vs. profundización" (Pellón, 2007b).

12 1951: Bélgica, Francia, Alemania, Italia, Luxemburgo, Países Bajos; 1973: Dinamarca, Irlanda, Reino Unido; 1981: Grecia; 1986: España y Portugal; 1990: Alemania, 1995: Austria, Finlandia, Suecia.

13 Estonia, Letonia, Lituania, Polonia, República Checa, Hungría, Eslovaquia, Eslovenia, Malta, Chipre.

14 La quinta ampliación de la Ue culmina con la entrada de Bulgaria y Rumania. Consultar Pellón (2007a). 
En sentido general, el objetivo de llevar a término el desmantelamiento del otrora sistema en las repúblicas de Europa del Este, propiciando su transición a un nuevo modelo de relaciones de producción, condujo al liderazgo comunitario a enfrentar una acelerada expansión, sin haber establecido los soportes institucionales necesarios para amortiguar el choque económico, político, social y cultural que se derivaría de ella. Por tanto, dicho proceso significó, en la práctica, la subordinación de un proyecto inicial, dirigido a constituir una Europa-potencia, capaz de reequilibrar multilateralmente los asuntos globales, por la concreción de una Europa-espacio, ampliada y poco compacta.

Algunos ejemplos ilustran, de manera particular, el citado panorama. Ante parte importante de la ciudadanía y del liderazgo político comunitario resultaba cuestionable la capacidad de la UE para asimilar a nuevos miembros en un marco de eficacia institucional. La "Estrategia de ampliación 2006-2007", en esencia, planteó la necesidad de incrementar la rigurosidad en la observancia de los requisitos previos a la adhesión de un nuevo miembro; así como el propósito de evitar nuevas ampliaciones en tanto no se ratificara un nuevo tratado (Unión Europea, 2006).

La legitimidad del proceso se encontraba particularmente cuestionada tras fracasar el pretendido Tratado Constitucional Europeo (TCE) (Unión Europea, 2003). El documento había constituido la respuesta, estimable o no, del liderazgo comunitario ante el propósito de alcanzar una mayor cohesión de sus miembros $y$, en sentido general, profundizar el proceso integracionista. Sin embargo, el Tratado resultó particularmente cuestionado en el 2005, luego del "no" francés y holandés en referéndum. El continuo declive de la legitimidad institucional se tradujo en un rechazo que procedía fundamentalmente, aunque no de manera exclusiva, de sectores populares, los cuales se percibían más inseguros frente a las políticas estimuladas o desarrolladas desde el entramado comunitario.

Así, en Francia y en Holanda (donde el Tratado fue rechazado), el 72 y el $63 \%$, respectivamente, de los trabajadores votaron en contra. Lo mismo ocurrió en Luxemburgo, donde a pesar de ser aprobado, el $62 \%$ de los trabajadores manuales que votaron lo hicieron en contra del Proyecto. En este sentido, encuestas mostraron que si hubiera habido referendos en Alemania y Dinamarca, la mayoría de los sectores de trabajadores hubieran estado también en contra (61 y $72 \%$ ) (Navarro, s. f.).

En el contexto en que fracasó el TCE, tres elementos socioeconómicos influían de manera específica en el descrédito de las políticas institucionales. Uno de ellos fue el desempleo, problema que afectaba particularmente a sectores y grupos etarios, alcanzando sus máximas cuotas entre los jóvenes, las mujeres y los trabajadores no calificados ${ }^{15}$.

15 A pesar de la disminución del desempleo a 7,1 \% en abril de 2007 en relación con el 7,9\% existente al cierre de 2006, se puede afirmar que la estrategia de empleo de la UE se centró en la desregulación del mercado laboral y el aumento del trabajo precario. 
Un segundo factor, quizás con menor visibilidad mediática, pero de igual trascendencia, ha sido la desigual redistribución de la renta, basada en un gran crecimiento del capital y un estancamiento de los beneficios del trabajador. Desde 1980 no han dejado de bajar los impuestos directos sobre las rentas más elevadas y las grandes empresas. Así, en la UE, de 2000 a 2008, las tasas superiores del impuesto sobre la renta y el impuesto de sociedades bajaron respectivamente 7 y 8,5 puntos. Esos cientos de miles de millones de euros de regalos fiscales se orientaron esencialmente hacia la especulación y la acumulación de riquezas por parte de los más ricos (Toussaint, 2011).

Uno de los ejemplos más visibles de este fenómeno se presenta en España. La aplicación de políticas fiscales regresivas ha favorecido que las grandes empresas espańolas obtengan cada vez más beneficios a costa del control salarial y del trabajo precario. Las ganancias de las grandes empresas en el 2006 y su incremento respecto al 2005 contrastaron con la pérdida del poder adquisitivo de los salarios. Concretamente, casi medio punto porcentual puesto que el incremento medio de los salarios fue del $3,7 \%$ frente a una subida del 3,24 en el Índice de precios al consumo. El Banco de Santander incrementó sus beneficios en el 22,1\%; Telefónica, en el 40,2\%; BBVA, en el $24,2 \%$, por solo citar algunos ejemplos (Pellón, 2010).

Un tercer elemento ha sido la ralentización del crecimiento del gasto público social por habitante. El crecimiento de tal gasto en el periodo 1990-2005 fue menor en la mayoría de países de la ue que en la década de los años ochenta del siglo pasado.

El rechazo al TCE, por parte de un número importante de sectores populares y en varios países de la UE, indicó que no se debió exclusivamente a situaciones locales, como pudo ser la impopularidad en Francia del entonces presidente Jacques Chirac, sino a la evolución de fenómenos que erosionaban sensiblemente el bienestar social europeo. Las tendencias generales evidenciaban el carácter estructural de los problemas y las desigualdades económicas, sociales y políticas existentes entre los países y las regiones de la Unión Europea.

En respuesta, y como parte de los artilugios que fueron diseñados para sustituir el TCE por el Tratado de Lisboa, se descartó la consulta popular en referéndum y dicha competencia fue traspasada a los parlamentos nacionales. La estratagema también implicó un cambio en la terminología del documento, lo cual llevó a eliminar las palabras constitución o constitucional.

Las divergencias de los Estados miembros referidas a las reglas del juego político, medios y fines del proceso integracionista en su conjunto, también constituyeron obstáculos que debieron sortear, durante el proceso de negociación, los promotores de ratificar e implementar el nuevo tratado.

Nuevamente, los puntos álgidos estuvieron condicionados por intereses y una lógica o razón de estado. Específicamente versaron sobre puntos sensibles de la dinámica institucional; entre los que se encontraron el peso de cada Estado y del Parlamento Europeo en el marco de los procesos decisorios de 
la UE, las atribuciones conferidas a la UE en los marcos de la PESC, el surgimiento y rol de un presidente permanente del Consejo, de la Alta Representante de la Unión para Asuntos Exteriores y Política de Seguridad, y el fortalecimiento o la ralentización de la supranacionalidad institucional.

$\mathrm{Al}$ respecto, las principales reclamaciones estuvieron a cargo de Polonia, Reino Unido y Holanda. Las posiciones asumidas por los hermanos Lech y Jaroslaw Kaczynski, entonces presidente y primer ministro respectivamente de Polonia, fueron una prueba clara de las contradicciones internas que genera la distribución de votos, y específicamente su incidencia en el sistema de toma de decisión de la UE. La representación polaca acudió a Bruselas dispuesta a limitar la pérdida de poder que le supuso la renuncia al Tratado de Niza, vigente hasta ese momento. Finalmente, consiguió extender el otrora sistema de votación hasta el 2014, ampliado en la práctica hasta el 2017, año en que debe entrar en vigor íntegramente un nuevo sistema.

Con el Tratado de Lisboa se proyectó incrementar la capacidad de la ue para adoptar decisiones, y con ese propósito se extendió el voto por mayoría cualificada a una veintena de disposiciones, que hasta ese momento requerían la unanimidad de los Estados representados en el Consejo. Respecto al Tratado de
Niza, también se flexibilizaron las denominadas llaves de bloqueo, pues, desde noviembre de 2014, el voto por mayoría cualificada solo debía estar respaldado por el 50\% de los Estados que representaran el $55 \%$ de la población, con medidas transitorias hasta el año $2017^{16}$.

No obstante, diversos elementos continúan ralentizando la dinámica institucional y los procesos decisorios en la UE. Este fenómeno es particularmente visible en ámbitos como el de la Política Exterior y de Seguridad Común (PESC), y la Política Europea de Seguridad y Defensa (PESD), donde se requiere la unanimidad de los Estados miembros para la adopción de decisiones ${ }^{17}$.

Existen varias cláusulas en el Tratado de Lisboa cuyo único propósito es ratificar el carácter intergubernamental de la pesc. Tras la solicitud de varios Estados, entre los que se destacaron Francia y Reino Unido, se especificó en el apartado 1 del artículo 24 del Tratado de la Unión Europea que las disposiciones referentes a la PESC, incluido lo relativo al Alto representante y al Servicio Europeo de Acción Exterior, no afectarían a las bases jurídicas, responsabilidades y competencias existentes de cada Estado miembro en relación con la formulación y conducción de su Política Exterior, su servicio diplomático nacional, sus relaciones con terceros países y su participación en organizaciones interna-

\footnotetext{
16 Para comparar las reformas propuestas en Lisboa con el otrora mecanismo decisión establecido en Niza consultar Perera Gómez (2002).

17 Es necesario señalar que existen cuatro excepciones a la norma de unanimidad. Decisiones por las que se define una acción o una posición de la Unión sobre la base de una decisión del Consejo Europeo, aplicación de las acciones o posiciones comunes, nombramientos de representantes especiales. La cuarta era una innovación del Tratado constitucional. Se aplica a las posiciones europeas adoptadas a raíz de una petición del Consejo Europeo.
} 
cionales, incluida la pertenencia de un Estado miembro al Consejo de Seguridad de las Naciones Unidas.

En este orden, también se enfatiza que en las disposiciones correspondientes a la PESC no se confieren nuevos poderes a la Comisión, ni se amplían las funciones del Parlamento Europeo. Otro elemento introducido en el Tratado de Lisboa, a petición del Reino Unido, contribuyó a relativizar los poderes conferidos al cargo de Alto Representante y debilitó las posibilidades de que el bloque proyectase una política exterior común. En este orden, se precisa que el Tribunal de Justicia de las Comunidades Europeas no es competente para juzgar litigios relativos a la interpretación o la aplicación de las decisiones tomadas en el marco de las Pesc y la política de defensa.

Aun cuando el nuevo tratado le otorgó personalidad jurídica a la UE, los factores mencionados continúan vulnerando sus niveles de participación o representatividad en organismos internacionales. El propósito es claro: se trata de impedir que el Tribunal de Justicia de las Comunidades Europeas menoscabe las competencias de los Estados en un ámbito tan vinculado a su soberanía.

Algunos especialistas, apoyados en la escaza capacidad de la uE para proyectar en el escenario internacional una sola voz, han calificado al bloque de enano político. Lo definido en el Tratado de Lisboa, en términos de PESC, también fue expresión de los intereses diferenciados, y de las propias asimetrías económicas, políticas y hasta culturales que existen entre los Estados miembros.

La quinta ampliación hizo particularmente visible este fenómeno. Los miembros provenientes de Europa central y oriental han demostrado que en los marcos institucionales no constituyen una periferia pasiva. Aunque sus alianzas son mutables y adoptan posiciones en dependencia de los temas, también tienen intereses comunes $y$, en determinadas cuestiones, se contraponen al liderazgo comunitario tradicional $^{18}$.

$\mathrm{Al}$ respecto, fue distintivo el apoyo brindado a Estados Unidos durante su agresión contra Irak (2003), a pesar de la oposición inicial de miembros tan influyentes como Alemania y Francia. Igualmente, ignorando una resolución del Parlamento Europeo contra la acción militar, líderes políticos de diversos Estados firmaron una declaración de apoyo a Washington y auxiliaron logística y militarmente la invasión, lo cual erosionó la proyección exterior del bloque, ante un tema tan sensible ${ }^{19}$. Otro ejemplo, en el ámbito de la seguridad y defensa, son las disonancias existentes entre los Estados comunitarios. La decisión polaca y checa, en el 2007, de introducir el escudo antimisiles norteamericano en sus respectivos territorios fue particularmente ilustrativa. Mientras estadounidenses, checos y polacos negociaron por su cuenta, el resto de la uE se inquietó, sobre todo por la falta de información y consulta sobre un proyecto

18 Los miembros de Europa central y oriental superan los votos requeridos para bloquear cualquier decisión.

19 Gran Bretaña, España, Italia, Portugal, Hungría, Dinamarca, Polonia y República Checa. 
que afectaría la seguridad del continente (Ramírez, 2007)

Las reformas contempladas en Lisboa también persiguieron brindar una mayor coordinación y cohesión política de los miembros en los marcos del Consejo Europeo ${ }^{20}$. Sin embargo, el dinamismo de esta institución se ha visto afectado por deficiencias estructurales que, a su vez, vulneran las posibilidades comunitarias de proyectar una política internacional más efectiva.

Con el nuevo Tratado se institucionaliza por primera vez la figura de un presidente permanente para la Unión Europea ${ }^{21}$. Este asume en su rango y condición, la representación de la Unión en los asuntos de política exterior y de seguridad común, sin perjuicio de las atribuciones del Alto Representante de la Unión para Asuntos Exteriores y Política de Seguridad. Ello evidencia, por una parte, las limitaciones del propio presidente comunitario en términos de la PESC, mientras que por otra, deja ver un mayor protagonismo del Alto Representante, entre cuyas competencias aparecen la de presidir el Consejo de Exteriores y Asuntos de Defensa, además de ostentar el cargo de vicepresidente de la Comisión Europea.

Una de las grandes interrogantes formuladas alrededor del nombramiento de un presidente para la UE, ha sido la coexistencia de este actor con las presidencias semestrales asumidas rotativamente por los miembros del bloque. La efectividad y necesaria complementariedad entre ambos actores constituye un reto en los marcos del contexto institucional. En ese sentido, y como resultado de las reformas contempladas en Lisboa, las presidencias semestrales experimentan una pérdida de relevancia y sus funciones pueden sintetizarse en la organización, el establecimiento de la agenda y la intermediación.

Los cambios implementados, respecto a la función de organización, son especialmente importantes. Hasta el momento, las presidencias asumían la organización y gestión de todos los trabajos del Consejo, de sus órganos auxiliares y del Consejo Europeo. Ahora, este último pasa a tener su propio presidente estable y la dirección de una de sus diez formaciones, la de Relaciones Exteriores, queda en manos de la Alta Representante.

Las presidencias semestrales pierden su competencia en materia de representación exterior, y las prioridades en este ámbito quedan marcadas, fundamentalmente, por las instituciones europeas correspondientes. Se trata de una pérdida notable, por el relieve político y el protagonismo mediático que implicaba

\footnotetext{
20 El Consejo Europeo estará compuesto por los jefes de Estado o de Gobierno de los Estados miembros, así como por su presidente y por el presidente de la Comisión. Participará en sus trabajos el alto representante de la Unión para Asuntos Exteriores y Política de Seguridad.

21 Este es elegido por mayoría cualificada en el Consejo Europeo para un mandato de dos años y medio, que puede renovarse en una ocasión. Entre sus funciones se encuentra garantizar la preparación y continuidad de los trabajos del Consejo Europeo en cooperación con el presidente de la Comisión, basándose en los trabajos del Consejo de Asuntos Generales.
} 
representar a los Estados miembros frente al resto del mundo.

Sin embargo, se mantiene cierto coprotagonismo. Particularmente en las cuestiones de ampliación, que son competencia del Consejo de Asuntos Generales, y en la proyección externa que poseen algunos consejos sectoriales, especialmente el de Economía y Finanzas, y el de Justicia e Interior. También resulta ostensible la posibilidad de que países con gran peso e influencia, como son los casos de Francia, Reino Unido o Alemania, puedan elevar el protagonismo de una presidencia semestral.

La crisis institucional y los impactos que debió afrontar el Tratado de Lisboa desbordan asuntos como el anquilosamiento de los procesos decisorios y la escasa capacidad de la UE para proyectar una política exterior y de seguridad verdaderamente común. La crisis institucional igualmente se vincula al descrédito e ilegitimidad de las políticas promovidas desde el entramado institucional. Además, pasa por los escasos niveles de participación, tanto del ciudadano comunitario como del Parlamento Europeo en los procesos decisorios de la uE, fenómeno que se ha denominado, incluso por parte del liderazgo político, déficit democrático institucional.

Conceder mayores atribuciones al Parlamento Europeo, promover la actuación de los parlamentos nacionales y desarrollar la democracia participativa con nuevos mecanismos de interacción entre ciudadanos e instituciones fueron algunos de los objetivos planteados en Lisboa, para paliar el denominado déficit (Unión Europea, 2003).

En ese orden, los aportes contemplados en Lisboa no dotaron al PE de nuevas competencia. Las reformas se vincularon con los procedimientos a través de los cuales la Eurocámara ejerce de conjunto con el Consejo el Poder Legislativo. Específicamente se instrumentaron cambios en el denominado procedimiento de codecisión, que pasó a instituirse como un procedimiento legislativo ordinario $^{22}$.

El citado procedimiento, técnicamente, otorga al Legislativo el poder de rechazar una decisión adoptada por el Consejo. Sin embargo, tal acción solo puede concretarse con la aprobación de la mayoría absoluta de sus miembros. En los casos en que se alcancen los requisitos establecidos para obstaculizar una iniciativa, y como paso adicional, las impugnaciones del órgano son estudiadas por un comité de conciliación. En la práctica, tras los múltiples tecnicismos que presenta el nuevo Tratado de la Unión, el pe continúa siendo víctima y partícipe del déficit democrático de la Unión, básicamente mantiene un carácter político-consultivo, con insuficientes atribuciones legislativas, y una limitada incidencia en la toma de decisiones.

Los poderes de la Comisión Europea, en el ámbito legislativo, vienen a engrosar el grupo de factores que quebrantan la credibilidad

22 Otros procedimientos son: "De cooperación” (pronunciándose sobre las propuestas de la Comisión Europea) y "De dictamen conforme" que somete a ratificación por el Parlamento la celebración de acuerdos internacionales (negociados por la Comisión), así como cualquier nueva ampliación de la Unión. 
del PE ante los ciudadanos. El nuevo Tratado no solo corrobora la iniciativa legislativa de la Comisión, sino que fortalece sus competencias, al otorgarle el poder de modificar "algunos elementos no esenciales" de un acto legislativo ${ }^{23}$.

En ese orden, otras reformas promovieron la actuación de los parlamentos nacionales. El artículo Siete del protocolo Segundo indica el procedimiento que les permite incidir sobre el proceso legislativo europeo. Con ese propósito, se incrementó el tiempo dispuesto para que los parlamentos nacionales se pronuncien sobre los proyectos legislativos europeos, específicamente sobre el principio de subsidiariedad ${ }^{24}$. También quedó reducida la proporción de parlamentarios requeridos para que la Comisión Europea reconsidere una propuesta legal.

Aunque hay un avance, los procedimientos descritos conservan un radio de acción limitado. Los parlamentarios no pueden manifestarse sobre el fondo de los proyectos legislativos de la Unión, sino respecto a su conformidad jurídica: referido al principio de subsidiariedad. Quedan excluidos, por tanto, de poder desestimar un acto comunitario.
Un peso igualmente discreto ha sido conferido a la participación de los ciudadanos. El "Derecho de iniciativa ciudadana" 25 , aunque es uno de los aportes más publicitados de Lisboa, no ha devenido en un instrumento efectivo de democracia participativa. Entre el año 2011 y el 2015 se lanzaron 51 iniciativas y en ninguna ocasión los ciudadanos implicados alcanzaron su objetivo: que se legislase sobre el tema ${ }^{26}$.

El derecho de petición ciudadana ya se encuentra estrictamente enmarcado y debe referirse de manera exclusiva a la aplicación de los Tratados (Khalfa, 2007). En este campo, una iniciativa no puede parar, revertir o negar legislación. Tampoco puede referirse a un tema que se esté tramitando. Un ejemplo de ello es el de la petición "Stop Tтाр", ${ }^{27}$ que aunque recogió más de un millón de firmas, la Comisión dictaminó que no cumplía los requisitos.

Acerca del impacto que puede producir una iniciativa ciudadana frustrada y las dificultades que deben vencer los ciudadanos comunitarios para promoverla, el eurodiputado György Schöpflin (2015) planteó:

Cada vez que se rechaza una iniciativa que ha conseguido un millón de firmas, se crean un millón

\footnotetext{
23 Nuevo artículo 249 в, Tratado de Funcionamiento de la UE.

24 Según el principio de subsidiariedad la UE, excepto en los ámbitos de su competencia exclusiva, solo debe actuar cuando ello resulte más eficaz que la acción a escala nacional.

25 Gracias a esta medida, un millón de ciudadanos de la Unión que residan en al menos una cuarta parte de los Estados miembros pueden instar a la Comisión a presentar una propuesta de acto jurídico que consideren necesaria para la aplicación de los Tratados de la UE.

26 En el 2011 fueron aprobados los procedimientos y las condiciones requeridas para hacer efectiva una iniciativa ciudadana. Ver Reglamento (UE) 211/2011.

27 Tratado Trasatlántico de Comercio e Inversión (TTIP).
} 
de euroescépticos. [...] Acepto que no es un instrumento fácil de poner en marcha, pero creo que se puede conseguir que funcione. Realmente, el mayor problema es que lanzar una iniciativa es mucho más caro de lo que se había pensado. Las que han llegado a algún sitio han tenido algún apoyo, y preocupa que intervengan grandes empresas.

El Tratado de la ue también reconoce los derechos, las libertades y los principios enunciados en la Carta de Derechos Fundamentales ${ }^{28}$. Sin embargo, el alcance de la Carta se ve limitado por varios factores. Como resultado de la negociación que dio luz al nuevo tratado, quedó eliminado el cuarto párrafo del artículo 6 del Tratado de la Unión Europea, el cual indicaba que esta otorgaría los medios necesarios para alcanzar los objetivos y la instrumentación de las políticas contempladas en la Carta. Como resultado, se vulneró la relación proporcional que debió existir entre las políticas públicas europeas y los enunciados derechos.

Por otra parte, su contenido se remite esencialmente a las prácticas y legislaciones nacionales, quedando suprimidas las posibilidades de crear un derecho social europeo, capaz de reequilibrar el derecho de la competencia con el bienestar social de amplios sectores poblacionales. Al respecto, el ámbito de la salud pública puede resultar representativo.

Tal como refleja el Tratado de Funcionamiento de la UE, los Estados miembros reafirman la responsabilidad de definir una política de salud e incluir un plan de recursos. Sin embargo, del Tratado quedaron excluidas históricas demandas que han tenido como fin indicar objetivos más precisos en el ámbito de la salud pública. Tal es el caso del establecimiento de montos mínimos de participación de los gastos de salud en el PIB, y una perspectiva de convergencia "hacia arriba" de los sistemas de protección social. Así, el propósito de equilibrar la gran disparidad de los sistemas de protección social, profundizada a partir de la ampliación de 2004, queda claramente erosionada.

Este fenómeno se hace particularmente visible en el actual escenario comunitario, signado por los impactos de la crisis económica y el incremento de las asimetrías entre los miembros del Norte y Sur ${ }^{29}$. Los numerosos programas de ajustes estructurales aplicados están jugando un papel decisivo en ello, además de las políticas fiscales altamente contractivas. Situación general que se refleja en los índices de desempleo, la precariedad laboral, el limitado consumo de los hogares, la baja demanda interna, y un incremento de las poblaciones en riesgo de pobreza y exclusión social. Estos problemas socioeconómicos, y el agravante envejecimiento poblacional que afecta al conjunto de la Unión, implican un reto significativo para la seguridad social comunitaria.

La implementación de políticas neoliberales, evidenciadas en las propias medidas

\footnotetext{
28 Carta de Derechos Fundamentales de 7 de diciembre de 2000, tal como fue adoptada en el 2007.

29 La situación económica de miembros como España, Grecia, Italia o Chipre resulta representativa de este fenómeno.
} 
anticrisis, han exacerbado el descrédito y la deslegitimación de las instituciones ante los ciudadanos del bloque. El euro escepticismo ha ganado espacios, cuya expresión política puede apreciarse en el ascenso de la extrema derecha. La representatividad de esta fuerza se ha incrementado en los últimos ańos significativamente; tanto a nivel nacional como comunitario.

En el orden institucional -bajo la presión de las deudas y los déficit acumulados, la necesidad de controlar o imprimir rigor al cumplimiento del Pacto de Estabilidad y Crecimiento, y de prever el estallido de nuevos desastres financieros- las instituciones europeas han reforzado las medidas y las políticas dirigidas a establecer una nueva gobernanza económica en la UE.

Como parte del gradual fortalecimiento de las estructuras de gobernanza, se ha provisto a la Comisión Europea de instrumentos que le permiten incidir en asuntos domésticos como el presupuesto nacional, las políticas sociales, el mercado laboral, los salarios y la comercialización de los servicios públicos. Posee además la potestad de emitir alertas específicas a los Estados miembros, y sancionar a aquellos que ignoren las "sugerencias" del Ejecutivo comunitario $^{30}$.

En este terreno, por tanto, se han visto fortalecidos los poderes supranacionales en la Unión, que ha hecho uso de estas nuevas competencias desde la firma del "Pacto por el Euro Plus", adoptado por 23 Estados de la UE en marzo de 2011.

La situación general se asocia al deterioro de la legitimidad democrática de la UE y al aumento del euroescepticismo. Los ciudadanos se encuentran más distantes de poder incidir en las políticas socioeconómicas que les afectan. La toma de decisión, incluso, puede llegar a ubicarse fuera del radio de acción de algunos gobiernos. En dicho contexto, un número reducido de actores económicos y políticos se afianza como epicentro del proceso integracionista, siendo Alemania el símbolo más visible de una correlación de fuerzas asimétrica, donde los más poderosos determinan, en importante medida, los destinos del resto.

\section{CONCLUSIONES}

Las reformas contempladas en el Tratado de Lisboa, instrumentadas en medio de la mayor crisis económica que ha vivido el modelo capitalista, constituyeron la respuesta del liderazgo comunitario ante la necesidad de paliar las múltiples vulnerabilidades que afrontaba el proceso integracionista, y específicamente en lo referido a su dinámica institucional.

Vistas en su evolución, y aunque no se pueda hablar en términos cualitativos, las reformas de Lisboa también respondieron al avance y profundización que ha experimenta-

30 La Comisión Europea está dotada de un nuevo mecanismo de toma de decisiones: votación por mayoría cualificada inversa. Las sanciones con arreglo al Procedimiento de Déficit Excesivo se adoptarán mediante este nuevo mecanismo, lo que significa que las multas propuestas por la Comisión se consideran aprobadas salvo si es revocada la decisión por una mayoría cualificada del Consejo. 
do el proceso integracionista. Un modelo que responde a los intereses del gran capital y, por consiguiente, arrastra tras de sí, en sus etapas naturales de desarrollo, las contradicciones implícitas del sistema capitalista.

Las propias disparidades que existen entre los Estados miembros, fundamentadas en diferencias socioculturales, políticas, económicas y la capacidad de influir en los destinos comunitarios, continúan ralentizando la posibilidad de que la UE experimente un cambio cualitativo en las normas y directrices de su funcionamiento interno.

Sin embargo, a la Luz del Tratado de Lisboa, las facultades que exhibe el entramado institucional comunitario no se pueden apreciar en otro mecanismo de integración a escala mundial. La uE hace ostensible su condición como actor global, particularmente en aquellas esferas donde es capaz de actuar de manera conjunta, como resultado de las competencias que han transferido los Estados miembros a las instancias supranacionales. Tal es el caso de la denominada Política Comercial Comunitaria, la Política Agraria Común, o la Política Monetaria.

En el ámbito de la Pesc, la ue no se proyecta de igual modo. La aplicación del Tratado de Lisboa no ha dotado a la Unión de nuevas competencias, por lo cual, continúa recayendo en los Estados miembros el poder soberano de interpretar y ejecutar, acorde a sus intereses, lo que en este espacio se decide a nivel comunitario. La flexibilización de los procesos de toma de decisión continúa sin impactar significativamente en este espacio, lo que se expresa en el anquilosamiento o la ralentización de la dinámica institucional.
El presidente del Consejo de la UE, el Alto Representante para Asuntos de Exterior y Política de Seguridad, y el propio Servicio Exterior Europeo se mantienen limitados por el carácter intergubernamental de la PESC y del propio Consejo, subsistiendo las dificultades para que la Unión proyecte una política verdaderamente común.

El propósito de alcanzar una mayor participación ciudadana en el curso de los acontecimientos políticos y económicos a nivel regional, pese a las reformas contempladas en Lisboa, no ha sido alcanzado. Los instrumentos jurídicos tampoco han garantizado la aplicación de los asuntos tratados en la Carta de Derechos Fundamentales. Factores que continúan lacerando la legitimidad institucional ante los ciudadanos comunitarios.

Los efectos de la crisis económica también han dado mayor visibilidad a las vulnerabilidades del proceso, y al carácter estructural de los problemas. Ante ellos, y refutando los augurios del exprimer ministro portugués José Sócrates, no es posible hablar en términos absolutos del fin de la crisis institucional.

\section{REFERENCIAS}

Arrizabalo Montoro, X. (1996). Las privatizaciones en la Unión Europea (Crisis, ajuste y regresión social). Recuperado de http://www.ucm.es/Bucm/cee/doc/

Baro Herrera, S. (1997). Globalización y desarrollo mundial. La Habana: Editorial de Ciencias Sociales.

Borrell, J. (2006). El reto de la crisis constitucional. Bélgica: Oficina de Publicaciones Oficiales de las Comunidades Europeas. 
Briceño, J. R. (1994). La evolución institucional de la Unión Europea. Revista de Estudios Europeos (31), 60-75.

Burgerman, S. (2003). Soberanía estatal y responsabilidad comunitaria. Revista Jurídica, 16.

Comunidad de Madrid (s. f.). Origen y evolución de la Unión Europea. Recuperado de www.madrid. org.evolucion

Fernández Arias, A. M. (2006). ¿Cohesión en la UE? Revistas de Estudios Europeos (72).

Fernando Leugo, G. (2003). El desafío de la ampliación hacia el Este de la UE. Revistas de Estudios Europeos, xx (63).

Ferrero, R. (2007). Los olvidados o el incierto destino de los Balcanes occidentales. Recuperado de http:// www.revistapueblos.org/spip.php?article519

Figueras, x. (s. f.) ¿Puede Alemania salvar a la UE? Recuperado de www.blogoteca.com

Florentino Graupera, F. (2003). Diez años de asociación de la UE con países de Europa del Este. Balance crítico. Revistas de Estudios Europeos, XIX (59).

Khalfa, P. Comentarios al nuevo Tratado reformado de la UE. Recuperado de ATTAC.ES

Morgenthau, H. (1973). Politics among nations. The struggle for power and peace (5 ed.). New York: Alfred A. Knopf.

Navarro, v. (2007). La crisis de la Europa social. Recuperado de http://elpais.com/diario/2007/01/24/ opinion/1169593214_850215.html

Ospina, J. (2006). Unión Europea frena entrada de paises balcánicos, por ahora. Recuperado de http://www. dw.com/es/unión-europea-frena-entrada-depa\%C3\%ADses-balcánicos-por-ahora/a-2230927

Pellón Azopardo, R. (2007a). Bulgaria y Rumanía: ¿cuánto se integran realmente a la Unión Europea. Panorama Mundial (20).

Pellón Azopardo, R. (2007b). Situación actual del proceso de integración europeo: ampliación versus profundización (2004-2007). Revista de Estudios Europeos (77).

Pellón Azopardo, R. (2010). La gestión socioeconómica del PSOE: un balance crítico en el contexto de la huelga general del 29-S. Recuperado de www. kaosenlared.net/noticia/gestion-socioeconomicapsoe-balance-critico-contexto-huelga-general-29

Perera Gómez, E. (2002). Ampliación y reforma institucional en la UE._Revista de Estudios Europeos, $\mathrm{xx}(61)$.

Perera Gómez, E. (2004). Constitución Europea. ¿¿Un futuro diferente? Revista de Estudios Europeos, $\mathrm{xx}(67)$.

Vasapollo, L. (2002). La UE se extiende al oeste. Notas para una investigación. Revista de Estudios Europeos, $\mathrm{xx}(62)$.

Ramírez, M. (2016). La UE intenta entrar en el debate sobre el escudo antimisiles. Recuperado de http://elmundo.es/papel/2007/03/15/mundo/2097982_impresora.html

Torreblanca, J. I. (2004). Claves para entender la abstención en las elecciones europeas. Recuperado de http://www.realinstitutoelcano.

Toussaint, E. (2011). Ocho propuestas urgentes para otra Europa. Recuperado de www.cadtm.org/Ochopropuestas-urgentes-para-otra

Unión Europea (1951). Tratado constitutivo de la CECA. Recuperado de http://eur-lex.europa.eu/legalcontent/Es/TXT/?uri=URISERV\%3Axy0022

Unión Europea (1957). Tratado constitutivo de la CEE $y$ EURATON. Recuperado de http://eur-lex.europa. eu/legal-content/Es/TxT/?uri=uriserv\%3Axy0024

Unión Europea (1965). Tratado de fusión de los ejecutivos. Recuperado de Bruselas: Oficina de Publicaciones Oficiales de las Comunidades Europeas.

Unión Europea (2003). Tratado por el que se establece una constitución para Europa. Bruselas: Oficina 
de Publicaciones Oficiales de las Comunidades Europeas.

Unión Europea (2006). Estrategia de ampliación y principales retos 2006-2007. Incluido en anexo el informe especial sobre la capacidad de la UE para integrar a nuevos miembros. Comunicación de la Comisión al Parlamento Europeo y al Consejo. Bruselas: Oficina de Publicaciones Oficiales de las Comunidades Europeas. 